\title{
"Johnny Poppers": a cause of serious ocular injury
}

\author{
Kerr MacAndie, Peter Kyle
}

\begin{abstract}
Aims/background-The causes of blunt ocular trauma are many and diverse. We present two cases of ocular injury caused by an unusual form of weapon called a "Johnny Popper". There follows a theoretical and experimental evaluation of the velocity of the projectiles fired by this device.

Methods-A Johnny Popper was constructed under expert guidance. The elastic properties of the device were measured and this allowed calculation of a theoretical exit velocity of the projectiles fired. The weapon was subsequently fired under test conditions which permitted the exit velocity of the projectiles fired to be measured directly.

Results-The theoretical velocity of the projectiles was calculated as $80 \mathrm{~ms}^{-1}$ and the experimentally measured velocity was $57 \mathrm{~ms}^{-1}$.

Conclusions-Johnny Poppers are a previously undescribed and unique form of home made weapon. They are intended for playful mischief, but have the potential to cause serious ocular trauma. (Br f Ophthalmol 1998;82:807-809)
\end{abstract}

Blunt ocular trauma has many and diverse causes and reports in the literature include descriptions of injuries caused by commoner sources such as fists, ${ }^{1}$ air rifle pellets, ${ }^{23}$ and squash balls, ${ }^{4}$ and the more obscure, such as luggage straps, ${ }^{5}$ batons used for baton twirling, ${ }^{6}$ car airbags, ${ }^{7}$ exploding beverage bottles, ${ }^{8}$ and paint pellets fired in "war games". 9

We present two cases of blunt ocular trauma, both of which were caused by a most unusual type of home made catapult known as a "Johnny Popper".

This is followed by a study in which the construction of a Johnny Popper is described, and the velocity characteristics of the projectiles fired are discussed.

Department of Ophthalmology, Southern General Hospital NHS Trust, Glasgow G51 4TF K MacAndie P Kyle

Correspondence to: Kerr MacAndie, Department of Ophthalmology, Southern General Hospital NHS Trust, 1345 Govan Road, Glasgow G51 4TF.

Accepted for publication 29 January 1998

\section{Patients}

CASE 1

An 8 year old boy was referred to our department from accident and emergency with a right hyphaema, having been struck in the right eye by a stone fired from a Johnny Popper. On examination, unaided visual acuity in the right eye was $6 / 6$, there were multiple, parallel, linear corneal abrasions and a $1.9 \mathrm{~mm}$ hyphaema. There was no evidence of a retained foreign body, intraocular pressure was normal, and the retina was flat with no tears, holes, or commotio retinae. He was treated with a com- bination of topical antibiotic and steroid drops and made an uneventful recovery with unaided visual acuity maintained at $6 / 6$ at follow up.

CASE 2

A 9 year old boy was referred to our department from accident and emergency with decreased visual acuity of the left eye, having been struck in the left eye by a projectile fired from a Johnny Popper. At presentation the visual acuity of the left eye was reduced to hand movements perceived in four quadrants. There was a large, central corneal abrasion, mild corneal oedema with folds in Descemet's membrane, and a small hyphaema with $3+$ of red cells in the anterior chamber. Intraocular pressure in the left eye was $18 \mathrm{~mm} \mathrm{Hg}$. There was a dull red reflex and no view could be obtained of either the lens or the fundus.

Three days later the visual acuity of the left eye had improved to counting fingers at 0.5 metre and the anterior chamber had cleared, revealing a marked posterior subcapsular cataract. The retina appeared flat. A further 3 weeks later the visual acuity of the left eye was counting fingers at 1.5 metres and a mature cataract prevented any view of the fundus. B-scan ultrasonography confirmed the absence of a retinal detachment.

\section{Materials and methods}

We wished to determine the following characteristics of Johnny Poppers: how were they constructed and what was the velocity of the fired projectile?

A detailed interview was held with the patient in case 2 and a Johnny Popper was constructed under his direct supervision and guidance as follows. A finger was cut from a rubber glove and the open end was attached to the severed neck and mouth of a plastic drinks bottle with adhesive tape (Fig 1).

The device is used as follows: a projectile (most commonly a dried, processed pea) is dropped into the finger of the glove; the mouth

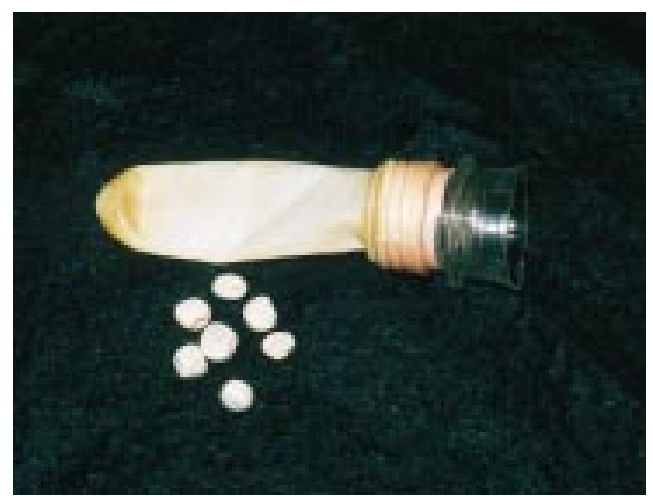

Figure 1 Construction of a fohnny Popper. 


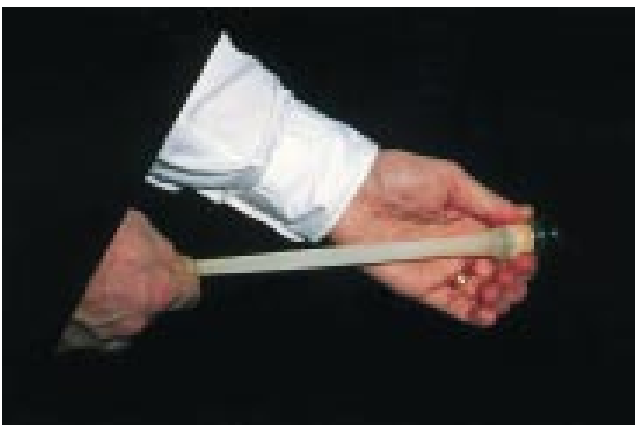

Figure 2 Firing projectile from a fohnny Popper.

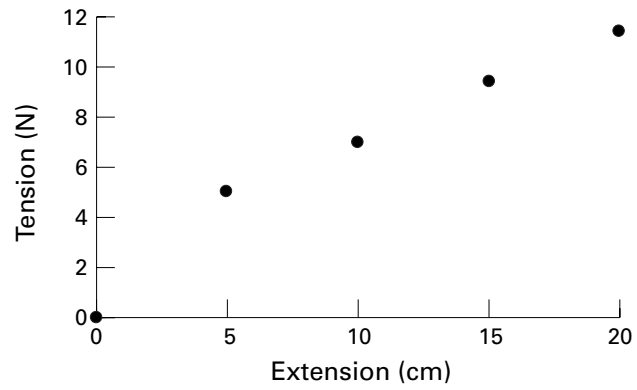

Figure 3 Plot demonstrating the linear relation between the extension of the elastic component of the fohnny Popper and the tension produced.

of the bottle is then held in one hand with the open end pointed towards the intended target, while the other hand pulls back the projectile within the finger of the glove and then releases the finger of the glove, firing the projectile (Fig 2).

In order to calculate a theoretical velocity of the projectile, a strain gauge was attached to the finger of the Johnny Popper and a graph was plotted of tension against extension (Fig 3). Hooke's law was used to calculate the strain potential energy stored at an extension of 20 $\mathrm{cm}$. Using the principle of conservation of energy, this was converted to kinetic energy and a theoretical velocity was then derived using the average mass of a dried pea as the projectile.

As the device makes a loud noise, it was presumed that a considerable amount of the strain potential energy would be dissipated as sound energy, thereby resulting in an actual velocity below that predicted by the above equations. A simple experiment was therefore conducted.

Two light gates were set $20 \mathrm{~cm}$ apart along the length of a metal tube (Fig 4). Each light gate was set up to produce a spike against a time scale on a cathode ray oscilloscope (CRO) when the light beam between source and sensor was broken. Several projectiles were fired from a Johnny Popper through the metal tube, passing through both light gates in sequence, thereby producing two separate spikes on the CRO. The distance between the spikes on the CRO represented the time taken for the projectile to travel $20 \mathrm{~cm}$ and this allowed direct calculation of the velocity. The experiment was repeated until a reproducible maximum velocity was found.

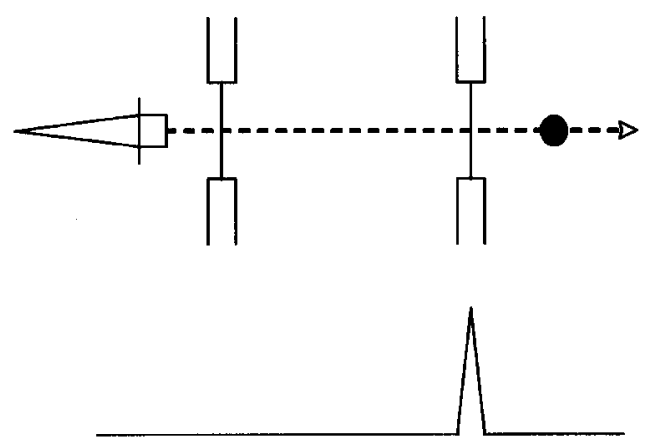

\section{r}

Results

Hooke's law states that:

$\mathrm{T}=\lambda \mathrm{x} / \mathrm{a}$

where $T=$ tension in string $(\mathrm{N}), \lambda=$ modulus of elasticity of string $(\mathrm{N}), \mathrm{x}=$ extension of string $(\mathrm{m}), \mathrm{a}=$ natural length of string $(\mathrm{m})$.

Hooke's law can be extended to derive the following equation:

$\mathrm{W}=\lambda \mathrm{x}^{2} / 2 \mathrm{a}$

where $\mathrm{W}=$ work done in stretching string $(\mathrm{J})$, $=$ strain potential energy $(\mathrm{J})$.

From the original data, we calculated that the strain potential energy stored by a Johnny Popper at an extension of $20 \mathrm{~cm}$ was $1.1 \mathrm{~J}$.

Assuming that all of this strain potential energy was converted to kinetic energy, we derived a theoretical exit velocity for the projectiles according to the following equation: $\mathrm{E}=1 / 2 \mathrm{mv} v^{2}$

where $\mathrm{E}=$ kinetic energy $(\mathrm{J}), \mathrm{m}=$ mass of projectile $(\mathrm{kg}), \mathrm{v}=$ speed $\left(\mathrm{ms}^{-1}\right)$.

Using the average mass of a typical projectile, the calculated theoretical exit velocity of the projectile was $80 \mathrm{~ms}^{-1}$.

With the data collected from the experiment using the light gates, the actual exit velocity of the projectile was calculated according to the following equation:

$\mathrm{v}=\mathrm{d} / \mathrm{t}$

where $\mathrm{v}=$ speed of projectile $\left(\mathrm{ms}^{-1}\right), \mathrm{d}=$ distance travelled $(\mathrm{m}), \mathrm{t}=$ time $(\mathrm{s})$.

The peak exit velocity measured by this method was $57 \mathrm{~ms}^{-1}$.

To put these results into perspective, a pellet fired from a spring loaded airgun travels at around $54 \mathrm{~ms}^{-1}$ (information from world wide web, http://www.recguns.com/IIIG3.html).

\section{Discussion}

These are the first reported cases of ocular injury caused by Johnny Poppers. The devices appear to be popular with the $8-10$ year old age group and its popularity is due to a combination of ease of construction and use, portability, potential for playful mischief, and ease of 
concealment within the classroom. Serious ocular injury is unintentional, but given the velocity of the projectiles fired, a misdirected shot is capable of inflicting significant damage.

As a final note, the authors wonder if the original Johnny Poppers were constructed using a condom (colloquial "Johnny") instead of a rubber glove, hence giving rise to the unusual name.

We thank our patient for showing us how to construct a Johnny Popper, Mrs Eileen McLaughlin for photographic work, and the staff of the medical physics department at the Southern Genera Hospital for their enthusiasm in setting up the experimental equipment.

Funding: none

Conflict of interest: none.
1 Beck SR, Freitag SL, Singer N. Ocular injuries in battered women. Ophthalmology 1996;103:148-51.

2 Moore AT, McCartney A, Cooling RJ. Ocular injuries associated with the use of airguns. Eye 1987;3:422-9.

3 Sternberg P Jr, de Juan E Jr, Green WR, et al. Ocular BB injuries. Ophthalmology 1984;91:1269-77.

4 Kahle G, Dach T, Wollensach J. (Eye injuries in squash) (German). Klin Monatsb Augenheilkd 1993;203:195-9.

5 Gray RH, Menage MJ, Cook SD, et al. Eye injuries caused by elasticated straps. BMF Clin Res (Ed) 1988;296:1097-8. 6 Fern AI, Kyle P, Allan D. Baton twirling: another cause of eye injury. Br f Ophthalmol 1987;71:931-2.

7 Duma SM, Kress TA, Porta DJ, et al. Airbag-induced eye injuries: a report of 25 cases. $\mathcal{F}$ Trauma 1996;41114-9.

8 Mondino BJ, Brown SI, Grand MG. Ocular injuries from exploding beverage bottles. Arch Ophthalmol 1978;96: 2040-1.

9 Mamalis N, Monson MC, Farnsworth ST, et al. Blunt ocular trauma secondary to "war games". Ann Ophthalmol 1990;22:416-8. 